\title{
Surgical treatment of recurrent ventricular tachycardia
}

\author{
S. Nitter-Hauge and O. Storstein \\ From Medical Department B, University Hospital, Rikshospitalet, Oslo, Norway
}

In rare instances, recurrent ventricular tachycardia may continue in spite of all therapeutic measures, including combinations of antiarrhythmic agents in maximum doses. In these circumstances, sympathectomy was performed in 5 patients, 4 with ischaemic heart disease, in an attempt to control paroxysmal ventricular tachycardia which had repeatedly occurred for from 6 weeks to 24 months. Abolition of the abnormal ventricular activity was obtained in 2 patients who have remained free from arrhythmia for 2 to 8 years. The operation had no effect on 2 patients, and only a temporary effect on one. In another I2 patients, a focal asynergic area (3 patients) or ventricular aneurysm (9 patients) was resected in order to control recurrent ventricular tachycardia after myocardial infarction. Abolition of the ventricular irritability was obtained in 7 patients, all remaining well from I month to $I_{2}^{\frac{1}{2}}$ years after the operation. Three patients died in the immediate postoperative period. A temporary effect was seen in 2 patients, of whom I was later reported to have died.

Ventricular tachycardia is a serious arrhythmia and is a manifestation of underlying ischaemic heart disease, severe congestive heart failure, myocarditis, or drug intoxication. Antiarrhythmic drugs, electrical countershock, or rapid electrical pacing are usually successful in controlling the majority of episodes (Gianelly et al., 1967; DeSanctis, 1965; Friedberg, Lyon, and Donoso, 1970). Recurrent attacks of ventricular tachycardia may, however, continue in spite of all these therapeutic measures, and the mortality of the patients with these arrhythmias is greater than that of patients with comparable conditions but without these arrhythmias (Armbrust and Levine, 1950). Combinations of drugs and pacing have also proved inadequate but better results were claimed when bilateral sympathectomy was performed (Estes and Izlar, 196I). More recently, there have also been scattered reports of curing refractory ventricular tachycardia after myocardial infarction by excision of a persisting focal asynergic or aneurysmal area of the left ventricular wall (Hunt, Sloman, and Westlake, 1969; Magidson, 1969; Ritter, 1969; Thind, Blakemore, and Zinsser, 197I). At present, however, evaluation of the role of these two methods in treating ventricular tachycardia is based upon reports of solitary cases, and information regarding long-term results is scanty.

In this study, we describe our clinical experience with bilateral thoracic sympathectomy in 5 patients

Received 16 April 1973. with recurrent ventricular tachycardia secondary to coronary artery disease or myocarditis. In addition, 12 patients with recurrent ventricular tachycardia after myocardial infarction have been followed up to assess the effect of infarctectomy.

\section{Patients and methods}

The case records of 17 patients undergoing operations for recurrent ventricular tachycardia were reviewed. For the present purpose, recurrent ventricular tachycardia denotes paroxysmal tachycardia of longer duration, terminated either by pharmacological or electrical intervention and reappearing spontaneously within minutes to hours. All patients failed to respond to prophylactic regimens including procainamide, quinidine sulphate, diphenylhydantoin sulphate, and propranolol, in various combinations.

The patients were men, varying in age from 26 to 66 years. The time intervals between the first attack of ventricular tachycardia and the operation varied from a few weeks to several years. A total of 5 patients underwent bilateral thoracic sympathectomy (Table I). Of these, 4 patients had coronary artery disease (Cases I-4), and one patient had cardiomyopathy of undetermined aetiology (Case 5). None of these patients had electrocardiographic changes suggesting the presence of ventricular aneurysm, but left ventricular angiography was not done in all cases. The remaining 12 patients (Table 2) had well-documented ischaemic heart disease with clinical and electrocardiographic evidence of recent (Cases I-3) or old (Cases 4-I2) myocardial infarction. Left heart catheterization with ventricular cineangiography revealed either localized akinesis or dyskinesis of a portion of anterior left ventricular wall or apex, or a true ven- 
TABLE I Recurrent ventricular tachycardia treated with sympathectomy

\begin{tabular}{|c|c|c|c|c|c|}
\hline $\begin{array}{l}\text { Case } \\
\text { No. }\end{array}$ & $\begin{array}{c}\text { Age } \\
(y r)\end{array}$ & Diagnosis & $\begin{array}{l}\text { Interval from } \\
\text { onset of ventricular teachycardia to } \\
\text { cardiac surgery }\end{array}$ & $\begin{array}{l}\text { Effect on } \\
\text { arrhythmia }\end{array}$ & Outcome \\
\hline $\mathbf{r}$ & 50 & IHD & $6 \mathrm{wk}$ & No response & Sudden death after $6 \mathrm{mth}$ \\
\hline 2 & 26 & Myocardial infarction & 14, & & Died in hospital after 4 wk \\
\hline $\begin{array}{l}3 \\
4\end{array}$ & $\begin{array}{l}44 \\
67\end{array}$ & " & $\begin{array}{l}5 \mathrm{mth} \\
\mathrm{I} \frac{1}{2} \mathrm{yr}\end{array}$ & $\begin{array}{l}\text { Temporary relief } \\
\text { Good }\end{array}$ & $\begin{array}{l}\text { Sudden death after } 12 \mathrm{mth} \\
\text { Follow-up } 4 \mathrm{yr}\end{array}$ \\
\hline 5 & 35 & Cardiomyopathy & 2 & " & Follow-up 8 yr \\
\hline
\end{tabular}

tricular aneurysm in the same areas. The focal asynergic area or aneurysm was resected with the aid of cardiopulmonary bypass.

In the postoperative period, the patient's response to operation was classified into one of the following categories; I) good response indicates abolition of ventricular tachycardia with survival of the patient; 2) temporary relief indicates amelioration of the rhythm disturbances but production of other effects with later sudden death most probably resulting from arrhythmia; 3) no response indicates unresponsiveness of the ventricular tachycardia, with death of the patients in the immediate postoperative period.

\section{Results}

The patients have been divided into 2 groups according to the operations performed.

In the sympathectomized group (Table I) there was one early death in hospital due to ventricular fibrillation (Case 2). The remaining 4 patients were discharged from the hospital alive. In one of them (Case I) recurrent episodes of ventricular tachycardia continued unchanged. Another patient (Case 3) showed temporary relief from arrhythmia. Both these patients were later reported to have died suddenly in their homes after a short illness suggesting ventricular tachyarrhythmia. Two patients (Cases 4 and 5) showed definite improvement, except for a few, usually solitary, episodes of ventricular tachycardia in the first weeks after operation. They now have stabilized sinus rhythm on a moderate maintenance dose of conventional antiarrhythmic drugs.

Of the 12 patients treated with excision of left ventricular wall dyskinesis or aneurysm (Table 2), 3 patients died of ventricular fibrillation in the immediate postoperative period (Cases I, 2, and 12). The first 2 patients belong to the small subgroup of patients who were operated on in the early phase of acute myocardial infarction. The remaining 9 patients made an uneventful recovery from the surgical intervention. They all had sinus rhythm on a maintenance dose of digitoxin and a small dose of procainamide. Two of them (Cases 9 and ro) continued to have symptoms of heart failure and complained of palpitation. Of these 2 patients, I was later reported to have died suddenly at home after an episode suggestive of ventricular fibrillation. The remaining 7 patients, comprising nearly two-thirds of this group, have been followed for I month to $I \frac{1}{2}$ years. They all have stable sinus rhythm without

TABLE 2 Recurrent ventricular tachycardia treatcd with infarctectomy (Cases $I$ to 3 ) or aneurysmectomy (Cases 4 to I2)

\begin{tabular}{|c|c|c|c|c|c|}
\hline $\begin{array}{l}\text { Case } \\
\text { No. }\end{array}$ & $\begin{array}{l}\text { Age } \\
(y r)\end{array}$ & $\begin{array}{l}\text { Age of } \\
\text { infarct }\end{array}$ & $\begin{array}{l}\text { Interval from } \\
\text { onset of ventricular tachycardia to } \\
\text { cardiac surgery }\end{array}$ & $\begin{array}{l}\text { Effect on } \\
\text { arhythmia }\end{array}$ & Outcome \\
\hline $\begin{array}{r}1 \\
2 \\
3 \\
4 \\
5 \\
6 \\
7 \\
8 \\
9 \\
10 \\
11 \\
12\end{array}$ & $\begin{array}{l}66 \\
46 \\
62 \\
46 \\
65 \\
53 \\
60 \\
50 \\
55 \\
52 \\
62 \\
56\end{array}$ & 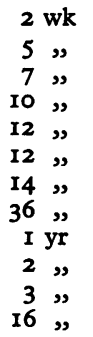 & 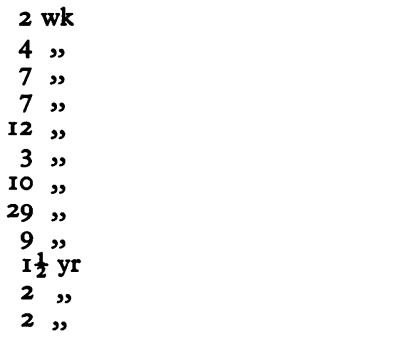 & $\begin{array}{l}\text { No response } \\
\text { Good" } \\
\text {," } \\
\text { ", } \\
\text { Temporary relief } \\
\text { Good," } \\
\text { No response }\end{array}$ & $\begin{array}{l}\text { Sudden death after } 2 \text { wk } \\
\text { Died after } 2 \mathrm{dy} \\
\text { Follow-up } \mathrm{r} \frac{1}{2} \mathrm{yr} \\
\text { Follow-up } 8 \mathrm{mth} \\
\text { Follow-up I yr } \\
\text { Follow-up } 6 \mathrm{mth} \\
\text { Follow-up } 7 \mathrm{mth} \\
\text { Follow-up } 6 \mathrm{mth} \\
\text { Follow-up I } \frac{1}{2} \text { year } \\
\text { Sudden death after Io mth } \\
\text { Follow-up I mth } \\
\text { Died after } 3 \mathrm{dy}\end{array}$ \\
\hline
\end{tabular}


ventricular tachyarrhythmias. At present, these patients are able to live a fairly normal life.

\section{Discussion}

In the present study, intractable paroxysmal ventricular tachycardia was the main clinical indication for operation. Treatment of the arrhythmia before operation had included all known specific antiarrhythmic drugs, and an operation was considered the last therapeutic resort.

The use of thoracic sympathectomy in the treatment of patients with ventricular tachycardia is based on the concept that myocardial catecholamines are directly involved in the genesis of ventricular ectopic activity. Sympathetic stimulation may also be assumed to lower the threshold for ventricular arrhythmias.

In animal experiments, surgical division of the sympathetic nerve supply to the heart decreased the incidence of ventricular fibrillation after coronary artery ligation (Harris, Estandia, and Tillotson, I95I), while results from other studies were less conclusive (Yodice, I94I). In man, recurrent supraventricular tachycardia was successfully treated by bilateral sympathectomy in two patients reported by Leriche and Fontaine (1929), and a beneficial effect of the operation was also noted in a series of patients with paroxysmal atrial tachycardia by White, Smithwick, and Simeone (1952). Cardiac sympathectomy also proved effective in inhibiting the recurrence of ventricular tachycardia in solitary cases reported by Estes and Izlar (I96I) and by Zipes et al. (I968). In our series, sympathectomy abolished ventricular tachyarrhythmia in 2 out of 5 patients, gave temporary relief in I patient, and had no effect on the remaining 2 patients. Apparently, sympathectomy under certain circumstances may prove effective in preventing ventricular arrhythmias, but the precise role and value of this therapy remains to be determined.

The rationale for surgical resection of an infarcted area in our patients was based on the assumption that an ischaemic zone represents a focus of electrical instability. It is likely that the dysrhythmias arise in the ventricle at the junction between wellvascularized and poorly vascularized myocardium, though this has never been definitely demonstrated. The possibility of circus movement (re-entry) occurring around the infarcted zone must also be considered; surgical intervention may interrupt the re-entry mechanism. Animal experiments have shown that resection of the focal asynergic areas after coronary artery ligation leads to stability of rhythm and easier ventricular defibrillation (Glass et al., 1968; Jude et al., 1968). In man, excision of an infarcted area of residual ventricular aneurysm has been reported to abolish recurrent ventricular tachyarrhythmia in 6 patients, published mainly as solitary cases (Hunt et al., 1969; Magidson, 1969; Ritter, 1969; Thind et al., 1971). The surgical intervention took place several months to more than one year after the acute coronary artery occlusion, with survival of 8 to 58 months after operation without recurrence.

As shown in our study, patients in whom recurrent ventricular tachycardia is associated with the existence of a left ventricular aneurysm may obtain considerable benefit from aneurysmectomy. In most of the patients, the transition from multiple potentially lethal episodes before operation to complete freedom from dysrhythmia after operation was striking. In a smaller group of these patients, the operation decreased the incidence of ectopic ventricular activity, but was not fully effective in the control of life-threatening ventricular arrhythmias. The results were less obvious in a small group of patients in whom infarctectomy was performed as an emergency operation in the acute phase of myocardial infarction. At present, since the role of surgery in treating such patients is ill defined and the risks are high, it should be considered only as a last therapeutic resort.

\section{References}

Armbrust, C. A., Jr., and Levine, S. A. (1950). Paroxysmal ventricular tachycardia: a study of one hundred and seven cases. Circulation, I, 28.

DeSanctis, R. W. (1965). Electrical conversion of ventricular tachycardia. Fournal of the American Medical Association, 191, 632.

Estes, E. H., Jr., and Izlar, H. L., Jr. (I96I). Recurrent ventricular tachycardia. A case successfully treated by bilateral cardiac sympathectomy. American fournal of Medicine, 31, 493.

Friedberg, C. K., Lyon, L. J., and Donoso, E. (1970). Suppression of refractory recurrent ventricular tachycardia by transvenous rapid cardiac pacing and antiarrhythmic drugs. Report of seven cases. American Heart fournal, 79, 44.

Gianelly, R., von der Groeben, J. O., Spivack, A. P., and Harrison, D. C. (1967). Effect of lidocaine on ventricular arrhythmias in patients with coronary heart disease. New England Fournal of Medicine, 277, 1215.

Glass, B. A., Carter, R. L., Albert, H. M., and Rosenberg, D. M. (1968). Excision of myocardial infarcts. Experimental and clinical studies. Archives of Surgery, 97, 940.

Harris, A. S., Estandia, A., and Tillotson, R. F. (I95I). Ventricular ectopic rhythms and ventricular fibrillation following cardiac sympathectomy and coronary occlusion. American fournal of Physiology, 165, 505.

Hunt, D., Sloman, G., and Westlake, G. (1969). Ventricular aneurysmectomy for recurrent tachycardia. Case report. British Heart fournal, 3I, 264.

Jude, J. R., Mobin-Uddin, K., Martinez-Farinas, L. O., Lombardo, C. R., and Smith, P. E., Jr. (1968). Surgical treatment of experimental myocardial infarction. Fournal of the American Medical Association, 203, 451. 
Leriche, R., and Fontaine, R. (1929). Chirurgie du sympathique. Revue Neurologique, $\mathrm{x}$, 1046.

Magidson, O. (1969). Resection of postmyocardial infarction ventricular aneurysms for cardiac arrhythmias. Diseases of the Chest, 56, 211.

Ritter, E. R. (1969). Intractable ventricular tachycardia due to ventricular aneurysm with surgical cure. Annals of Internal Medicine, 71, II 55 .

Thind, G. S., Blakemore, W. S., and Zinsser, H. F. (197I). Ventricular aneurysmectomy for the treatment of recurrent ventricular tachyarrhythmia. American fournal of Cardiology, 27, 690 .

White, J. C., Smithwick, R. H., and Simeone, F. A. (1952).
The Autonomic Nervous System, p. 288. Macmillan, New York.

Yodice, A. (194I). Sympathectomy and experimental occlusion of a coronary artery. American Heart fournal, 22, 545.

Zipes, D. P., Festoff, B., Schaal, S. F., Cox, C., Sealy, W. C., and Wallace, A. G. (1968). Treatment of ventricular arrhythmia by permanent atrial pacemaker and cardiac sympathectomy. Annals of Internal Medicine, 68, 591 .

Requests for reprints to Dr. Sigurd Nitter-Hauge, Medical Department B, University Hospital, Rikshospitalet, Oslo I, Norway. 